\title{
Exploration on Reform of Electronic Technology Course Design
}

\author{
Ying Guo \\ Tianjin University of Technology and Education, Tianjin 300222, China.
}

Abstract: Electronic technology course is one of the compulsory courses for students majoring in electricity, which occupies an important teaching position in the whole teaching system. At the same time, the teaching of this course has very high requirements for students' hand-on ability and practical ability. Especially in the context of teaching reform in higher vocational colleges, it is required that the professional talents to be trained must be innovative, practical and applied. Based on this, the teaching of electronic technology course must also be reformed and innovated, actively meet the needs of education and teaching reform, and improve the overall quality and efficiency of teaching. This paper introduces the current situation of electronic technology course design in colleges and universities in China, and analyzes the problems existing in the course implementation. In view of the innovation and practice of this course, some reform suggestions are put forward.

Keywords: Electronic Technology Course Design; Project Teaching; Innovation and Reform

\section{Introduction}

In the electrical specialty teaching in our university, the design of electronic technology course is an important practical teaching course in the whole teaching system. This course is a comprehensive practical training based on the basic experiments of analog circuit and digital circuit. It is a compulsory course for sophomores in summer semester, with 3 credits.

The course focuses on the simulation of multiple electronic circuits and the design and manufacture of a relatively complex functional circuit or electronic system by using general components and small and medium-sized integrated circuits. The purpose is to cultivate students' ability to solve practical problems by comprehensively using the relevant knowledge of electronic technology theory, improve circuit design level and practical skills, so as to cultivate research thinking and innovation ability, acquire new knowledge and experience to get comprehensive practical training.

\section{Problems in course design}

At present, there are three main problems in the design of electronic technology in our school.

\subsection{Weak design ability}

In the early stage of course design, students need to design the selected topics, but they are often looking for the existing design scheme, so their flexibility is weak. This is closely related to the usual training, and the improvement of design ability is not achieved overnight. Most of the time, teachers lack of guidance to students, which is not enough inspiration for students' thinking ability in teaching design. As time goes by, with fixed thinking and low innovation, students become "imitators" without novelty in design. Their overall creative ability is low and their practical ability is gradually weakened.

Copyright $₫ 2020$ Ying Guo

doi: $10.18686 /$ ahe.v4i10.2888

This is an open-access article distributed under the terms of the Creative Commons Attribution Non-Commercial License (http://creativecommons. org/licenses/by-nc/4.0/), which permits unrestricted non-commercial use, distribution, and reproduction in any medium, provided the original work is properly cited. 


\subsection{Too much welding practice}

Students use universal board for circuit welding in the existing scheme. Although it improves the ability of circuit layout welding, it also consumes much time, which is not conducive to the overall development of students. The arrangement of the whole course is not reasonable. It does not pay attention to uniformity and rationality. We should reasonably design the class hours of each chapter according to the principle of training practical ability of the course, and plan the time well so that students can comprehensively learn knowledge and master more professional practical ability, so as to truly promote the overall development of students.

\subsection{Unreasonable work distribution}

In a group of three students, although the whole practical process is completed by division of labor and cooperation, including information check, scheme design, circuit simulation, component purchase, installation and debugging, index detection and report writing, a small number of students are not fully engaged in their work and have not fully mobilized their learning enthusiasm. Although group teaching has certain advantages, it still needs teachers to master students' personality in order to "realize the reasonable and optimal allocation of human resources" and give full play to each student's specialty and nature. However, in the actual assignment tasks, teachers are randomly assigned, and the observation of students' personality is not comprehensive enough to meet the needs of students' comprehensive development, which leads to the limitation of students' comprehensive development, and the whole work assignment is not reasonable. Some students are good at and not good at, and have no chance to get comprehensive exercise.

Therefore, how to give full play to the dominant position of students in the process of course design and improve the enthusiasm and innovation of students' practice has become the key to improve the teaching effect and level of course design.

\section{Suggestions for improvement}

\subsection{Improve the means and methods of theoretical teaching}

How to inspire students" innovative consciousness and cultivate their practical ability in the course design of "electronic technology", so that students can integrate their basic theoretical knowledge into the design and analysis process of electronic system, and master the new technology and method of electronic design automation, we can introduce project teaching method into the theoretical teaching of analog circuit and digital circuit and exercise students' various abilities through the project design.

Project teaching method is to construct a situation for students to complete the corresponding projects and learn relevant professional knowledge, ability and quality. We can set up 2-4 small-scale electronic design processes in the teaching, so that students can receive the project, collect data, discuss the scheme, purchase components, install and debug, test data, summary report and display. The whole project design process enables students to realize the close relationship between theory and practice, and truly apply the theoretical knowledge to practical design.

Through project analysis, research and design, to prepare students for their future career. In the analysis process of actual production projects, students raise questions and solve them, and cultivate their ability to analyze and handle problems independently. Design projects such as: instrument amplifier design, simple competition responder design, water lamp control, etc.

For an independent project, students are responsible for the whole process of information collection, scheme design, project implementation and final evaluation. Through the project, students can master the basic requirements, progress and final results of the whole process and each part.

\subsection{Improve the teaching content of course design}

The three-week course design should be full of workload and reasonable division of work in groups so as to achieve the training purpose of students. Combined with the previous course "Electronic Circuit CAD" and the follow-up course "EDA", the teaching content can be fully combined with the knowledge learned by students, and the three-week course design content can be arranged as follows.

The first week: the group selected the analog-to-electronic topic to complete the design. Each member needed to use 
Multisim software to complete the circuit simulation and optimization. The team as a unit used the pocket laboratory to complete the debugging and acceptance of the circuit. The second week: the team selected the digital and electrical topics to complete the design. Each member needed to use QuartusII to design digital circuit system, download it to DE2 development board for verification, and draw PCB layout with Protel drawing software. The team purchased the required components for the unit. The third week: each group will launch the optimal PCB layout design, complete the board making parts such as transfer printing, corrosion and drilling, and then complete the installation and welding of components on the self-made circuit board, as well as carry out the system debugging and acceptance, and write the course design report.

Through circuit simulation optimization design, improve students' analysis and design ability and innovation ability; through drawing PCB layout and making board, students can participate in practice, stimulate learning interest and practical ability; through the application of QuartusII digital system, make students familiar with hardware programming language, and lay a foundation for subsequent courses.

In the course design process, students select topics in groups, but each student has to complete the tasks of Multisim simulation, QuartusII digital system verification and PCB drawing. After receiving comprehensive practical training, finally, the instructor will assess, accept and answer for each student. The content of course design is fully covered to effectively avoid unreasonable division of labor.

\subsection{Improve process management}

In the process of project implementation, the teacher formulates the process management plan according to the task execution sequence. When students encounter problems, they can carry out analysis and discussion, and guide students to refer to relevant textbooks and reference materials. For individual problems, individual guidance; for common problems, teachers can be answered by group. Learning with questions can achieve twice the result with half the effort. Division and cooperation, competition among groups, students' abilities in all aspects will be significantly improved. In the teaching process, teachers should also guide students to make daily records of project activities, so as to record the process of project development, problems encountered, solutions and the final effect.

At the end of the project, the students will demonstrate the effect of the works and explain the design principles, advantages and areas that need to be improved, summarize the experience and lessons learned, and finally submit the course design project report. Teachers make corresponding evaluation on students' course design process. On this basis, teachers evaluate the students' performance comprehensively according to the record of students' project situation, the content of collected data, the effect of summary report and demonstration, and the cooperation and attendance.

\section{Conclusion}

Through the course design, teachers should not only be limited to the teaching of professional knowledge, but also include humanistic knowledge, professional exploration knowledge and comprehensive application knowledge. The cultivation of ability focuses on acquiring knowledge actively, exploring and learning new knowledge, and mastering the practical application ability of finding and solving problems in problems. As a comprehensive index to measure talents, higher quality is the most important factor to evaluate talents, which is the specific embodiment of the development of cultural level and professional comprehensive ability. The ultimate goal of cultivating students is to realize the complementary, organic combination and common improvement of knowledge, ability and quality.

\section{References}

1. Liu D. Exploration on application of project teaching method based on KAQ theory in electronic technology course design. Education and Teaching Forum 2018; 1(2): 162-163.

2. Sis Y. Teaching reform and practice exploration of "electronic technology" course design. Journal of Electronics and Electrical 2017; 6: 148-150. 